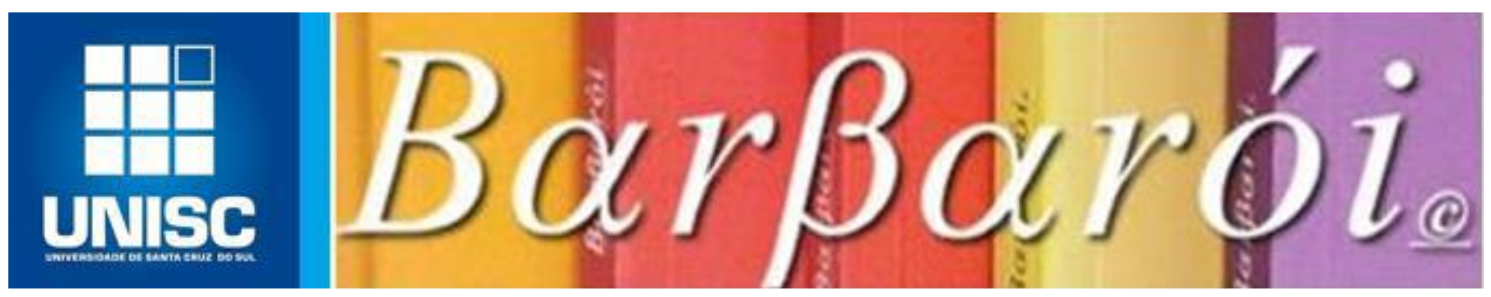

\title{
CONCEPÇÕES DE DEFICIÊNCIAS EM PROFISSIONAIS DE UMA UNIVERSIDADE DO INTERIOR PAULISTA
}

DOI: http://dx.doi.org/10.17058/barbaroi.v0i0.11309

\author{
$*$ \\ Lucia Pereira Leite \\ Universidade Estadual Paulista Júlio de Mesquita Filho - UNESP - Brasil \\ Taize de Oliveira \\ Universidade Estadual Paulista Júlio de Mesquita Filho - UNESP - Brasil \\ Hugo Ferrari Cardoso \\ Universidade Estadual Paulista Júlio de Mesquita Filho - UNESP - Brasil
}

$*$

\section{Resumo}

A participação de pessoas com deficiências em diferentes instâncias profissionais tem sido uma realidade cada dia mais frequente em função das políticas públicas que têm orientado essa prática. $\mathrm{O}$ estudo aqui retratado procurou identificar as concepções de deficiência em duas diferentes categorias de atuação profissional de uma universidade pública do Estado de São Paulo, a saber: docentes e técnicos administrativos. Parte-se da ideia de que as concepções sobre determinados fenômenos são norteadoras para as condutas sobre o mesmo, no caso, no trato em relação às pessoas com deficiências. Aplicou-se a escala de Concepções de Deficiência (ECD), como instrumento de coleta de dados, com os dois conjuntos de participantes. Os dados foram expostos as análises descritivas e inferenciais. Os resultados indicaram que tanto docentes como técnico-administrativos tendem a concordarem com as afirmações que coadunam com concepções que procuram interpretar a deficiência num viés mais social e cultural. Tais achados são importantes para que profissionais da Psicologia, em particular para aqueles que se encontram na área organizacional e do trabalho pensarem em formas de atuação para que as organizações possam de fato se constituírem como um espaço acolhedor às diferenças, com vistas ao desenvolvimento de diferentes grupos sociais.

Palavras chave: Pessoas com deficiência, concepção, organização.

\section{Introdução}

O paradigma de inclusão vem sendo construído por ações afirmativas que visam a participação de pessoas com deficiência em espaços sociais que até recentemente não tinham possibilidade de acessar, ou seja, estavam excluídas ou à margem dos mesmos. Muitos 
obstáculos são colocados a essa população, sendo um deles as barreiras atitudinais. Tais barreiras configuram-se na qualidade de preconceitos ou pré-julgamentos dirigidos aos sujeitos que se encontram na condição de pessoas com deficiência, muitas vezes atrelados a fatores sociais e individuais desfavoráveis, designando-os como incapazes, com menos valia, deficitários, defeituosos, dentre outros.

As políticas públicas na atualidade têm promovido a participação de segmentos minoritários em esferas sociais distintas no nosso país, como no mundo do trabalho e no campo educacional. No primeiro caso, destaca-se a Lei de Cotas $n^{\circ} .8213 / 91$, que se constituiu como fundamental para mudanças sociais, respaldando o direito de as pessoas com deficiência serem contratadas por empresas, e realizarem a atividade trabalhista. Já no campo da educação o acesso a níveis mais elevados de ensino tem sido uma preocupação, como a Lei 13.409, sancionada em 2016, que modifica a Lei de Cotas $n^{\circ} .12 .711$ de 2012, que limitava as cotas nas universidades federais somente para alunos de baixa renda, ou oriundos da rede pública, ampliando a reserva de vagas para que pessoas com deficiência também possam ser objeto das cotas de ingresso ao ensino superior público. Medidas como essa têm procurado redimir as barreiras impostas a esse segmento populacional. O artigo $3^{\circ}$, parágrafo IV da Lei $\mathrm{n}^{\circ}$. 13.146/2015, nominada de Lei Brasileira de Inclusão - LBI, que estabelece o Estatuto da Pessoa com Deficiência, definindo essas barreiras como sendo:

[...] qualquer entrave, obstáculo, atitude ou comportamento que limite ou impeça a participação social da pessoa, bem como o gozo, a fruição e o exercício de seus direitos à acessibilidade, à liberdade de movimento e de expressão, à comunicação, ao acesso à informação, à compreensão, à circulação com segurança, entre outros, classificadas em:

a) barreiras urbanísticas: as existentes nas vias e nos espaços públicos e privados abertos ao público ou de uso coletivo;

b) barreiras arquitetônicas: as existentes nos edifícios públicos e privados;

c) barreiras nos transportes: as existentes nos sistemas e meios de transportes;

d) barreiras nas comunicações e na informação: qualquer entrave, obstáculo, atitude ou comportamento que dificulte ou impossibilite a expressão ou o recebimento de mensagens e de informações por intermédio de sistemas de comunicação e de tecnologia da informação;

e) barreiras atitudinais: atitudes ou comportamentos que impeçam ou prejudiquem a participação social da pessoa com deficiência em igualdade de condições e oportunidades com as demais pessoas;

f) barreiras tecnológicas: as que dificultam ou impedem o acesso da pessoa com deficiência às tecnologias.

$\mathrm{Na}$ leitura dos dispositivos legais, percebe-se que o universo de obstáculos que as pessoas com deficiência se deparam no seu cotidiano é diverso e muito há que se fazer para que de fato a sociedade possa ser concebida como inclusiva e acolhedora a todos. No entanto, sabese que as ações são guiadas pelas concepções que se têm diante de determinado fenômeno e no caso da deficiência isso não é diferente. As discussões a respeito do tema de inclusão estão Barbarói, Santa Cruz do Sul, n.54, p.<153-170>,jul./dez. 2019 
subsidiadas por diferentes concepções, ou modo de compreender ou conceituar as deficiências, que, por sua vez, vão nortear práticas inclusivas ou não. Dito de outro modo, as atitudes humanas decorrem fortemente de como concebemos algo - material ou imaterial, sendo, portanto, a concepção em relação a algum fenômeno interessante objeto de investigação para a revisão de práticas sociais (DINIZ, 2003;.DINIZ, 2007; LEITE; OLIVEIRA; SERRANO, 2018; LEITE; OLIVEIRA, 2019).

Ao se estudar concepções é preciso dizer que elas podem ser compreendidas como conceitos que acarretam na representação social de um fenômeno. Adota-se nesse trabalho como fundamentação central para a compreensão de que as concepções orientam atitudes, como aventado por Thompson (1992), em que as concepções, por serem estruturas mentais compostas por crenças, conceitos, regras, significados e outros correlatos, contribuem para o sujeito agir a partir das mesmas, reproduzindo-os nas ações. No caso da deficiência, a forma de representar o sujeito que se encontra nessa condição está diretamente relacionada, segundo Omote (2004), como a audiência social percebe, reconhece e interage com tais diferenças. Alguns dos aspectos fundamentais nesse quesito são as possibilidades de barreiras decorrentes desse julgamento, por exemplo, um sujeito que identifica na pessoa com deficiência uma limitação orgânica orientará seu discurso e suas atitudes a partir dessa crença, com isso é muito comum se dirigir a esse sujeito com uma postura benevolente, assistencialista ou ainda como inferior aos demais. Tais entendimentos podem decorrer de uma tentativa de compensar as diferenças, entendidas como faltas ou déficits, em seus discursos ou práticas a partir de uma percepção enviesada ou limitada.

Algumas concepções podem facilitar a categorização depreciativa e a estigmatização do sujeito, causam efeitos negativos, seja no âmbito físico e/ou psicológico, tendo implicâncias diretas no curso de desenvolvimento desses. Fenômeno amplamente estudado por Goffman (1998/1963), o estigma pode ser compreendido como uma marca de cunho social atribuída às pessoas em função de alguns indivíduos exibirem características diferenciadas, e são tomadas como desviantes das normas aceitas e valoradas positivamente. Elas são vistas no contexto social em condição de inferioridade e atreladas a um profundo sentido depreciativo, por não terem atingido o pleno desenvolvimento humano. No caso das pessoas com deficiência o estigma muitas vezes decorre das diferenças corporais, sensoriais e/ou comportamentais apresentadas, que julgadas e categorizadas como atributos - marcas - negativas por aqueles que não as apresentam, atribuindo a conotação de estarem longe do considerado normal, por isso carregam a ideia de desviante ou anormais.

Para Gesser, Nuernberg e Toneli (2012) adotar a compreensão biológica da deficiência, acaba por prejudicar o entendimento do fenômeno como produto social que necessita de ações Barbarói, Santa Cruz do Sul, n.54, p.<153-170>,jul./dez. 2019 
pontuais no contexto para a garantia dos direitos fundamentais, ou seja, dificulta uma compreensão mais ampla, que envolva ajustes na sociedade para que todos possam usufruir de seus direitos independentemente das características individuais.

É preciso, portanto, romper com práticas sociais limitadas e excludentes, em que espera que esse se ajuste se adeque, quando o inverso deveria ser a regra. Dito de outro modo, é preciso conceber a deficiência como algo amplo e repleto de significados associados, localizando-a dentro do seu espaço de ocorrência, ou seja, da participação humana numa dada cultura, circunscrita a um período histórico. Com isso, várias interpretações são dadas na tentativa de melhor explicá-la (DINIZ, 2007; PALACIOS, 2008; NEPOMUCENO, 2019). Citam-se algumas delas, que ainda se encontram vigentes para clarificar o assunto.

Como já dito, a concepção biológica, igualmente discutida como modelo médico, identifica a deficiência como um atributo inerente ao indivíduo, adotando como referência o desvio de um padrão orgânico de normalidade, ou a presença de uma falha ou limite que acarreta um mau funcionamento geral ou específico de um dado organismo. Por sua vez, a concepção metafisica interpreta o fenômeno como sendo algo que transcende a condição humana, podendo estar atrelada a causas espirituais e/ou religiosas, ou a fatores sobrenaturais. Desse modo, é posta como fenômeno que não depende da atuação do homem (DINIZ, 2007; PALACIOS, 2008).

Pensando numa perspectiva que desloca do sujeito a deficiência, temos a concepção social, que a interpreta como uma condição orgânica diferenciada, associada a fatores causais de natureza: social, emocional, econômicas e/ou educacional, que influenciam a constituição humana. Portanto, nesta concepção os fatores que determinam a deficiência decorrem de fatores inerentes ao indivíduo e ao ambiente, e para interpretá-la é necessário descentralizar a análise no indivíduo e ver a deficiência como um fenômeno social, ou seja, é fazer das diferenças anátomo-fisiologias, comportamentais e/ou sensoriais, algo como parte da natureza humana e não como um atributo pessoal negativo (OMOTE, 1996; NEPOMUCENO, 2019; LEITE; OLIVEIRA, 2019).

Outra concepção que se aproxima do modelo social é a concepção histórico-cultural, que interpreta a deficiência como um fenômeno dinâmico, relacional e processual com base na relação entre o sujeito com alguma deficiência e a sociedade, sendo que esta última é pode facilitar ou não da promoção de desenvolvimento, decorrente das expectativas e de atitudes dirigidas a ele. Nessa perspectiva, entende-se que a deficiência é relativizada e significada historicamente no contexto de sua ocorrência, pois decorre de uma disfunção biológica que 
pode acarretar limitações, e como consequência uma barreira social, deixando esse sujeito em situação de desvantagem perante aos outros (LEITE; LACERDA, 2018).

Postas as definições reiteramos que é oportuno, para pesquisadores envolvidos com a temática, investigar ou melhor compreender quais as concepções de deficiência apresentadas por grupos distintos, uma vez que essas norteiam as práticas sociais profissionais e oueducacionais, teoria reiterada por Diniz (2007), Palacios (2008), Leite e Oliveira (2019) e podem contribuir ou não para que a inclusão de pessoas com deficiência ocorra.

\section{Objetivos}

Este estudo buscou retratar o posicionamento de funcionários de uma universidade pública - a saber, docentes e servidores técnicos administrativos - diante de enunciados que abordam diferentes concepções de deficiência. Desta maneira, objetivou-se comparar os posicionamentos apresentados pelas duas categorias de participantes, relacionando com as variáveis gênero e idade.

\section{Hipóteses investigadas}

Para o alcance das finalidades propostas, o estudo pautou-se nas seguintes hipóteses: a) se o contexto universitário promove a concordância com concepções sociais e históricoculturais devido ao caráter cientifico do contexto (OLIVEIRA; PANASIEWICZ, 2014) ; b) se a cultura ocidental promove maior participação religiosa conforme a idade, o que implicaria em aumento de concordância com pressupostos metafísicos a respeito de fenômenos (MOREIRAALMEIDA et al., 2010); c) se é possível identificar maior envolvimento das mulheres com crenças religiosas/metafisicas (ROSADO-NUNES, 2005).

\section{Método}

\section{Participantes}

A amostra deste estudo contou com a participação de 484 funcionários de uma universidade pública, distribuídos em dois grupos. O primeiro composto por 252 docentes, e outro constituído por 232 técnicos administrativos. Do total 271 participantes eram mulheres e 213 homens, com idade variando entre 22 e 73 anos.

\section{Instrumentos}

O instrumento utilizado na coleta de dados foi a Escala de concepções de deficiência A ECD (LEITE; LACERDA, 2013). Constitui-se num instrumento de pesquisa composto de Barbarói, Santa Cruz do Sul, n.54, p.<153-170>,jul./dez. 2019 
20 asserções que retratam quatro diferentes concepções de deficiência (biológica; social, metafísica e histórico-cultural), apresentadas na forma de cinco sentenças não consecutivas de cada enfoque. Para cada assertiva o respondente deve assinalar uma única opção de resposta, indicando seu grau de concordância, em escala do tipo Likert, constituída de cinco pontos ordenados, indicando desde discordância até concordância total, passando pela indiferença.

\section{Procedimentos}

É oportuno informar que este estudo conta com parecer favorável do Comitê de Ética para a sua realização (protocolo $n^{\circ}$ 13476713.5.0000.5398 - CAAE/Plataforma Brasil). Em virtude da universidade em que se realizou a pesquisa se constituir em unidades universitárias distribuídas por todo o estado de São Paulo, a aplicação da ECD se deu à distância, de modo virtual. Os dados foram coletados, ao final de 2014, por meio de formulário eletrônico de preenchimento voluntário, em que não era necessária a identificação do respondente, apenas dados de ano de ingresso no setor, idade, sexo, faculdade e unidade universitária vinculada.

\section{Análise de dados}

Os dados foram analisados com o auxílio do pacote estatístico IBM SPSS Statistics Base. Foram realizadas as análises descritivas gerais dos dados, como cálculo de frequência, média, mediana e desvio-padrão. Embora a pesquisa tenha um grande número de participantes, o que implicaria supor uma população normalmente distribuída, o teste de normalidade indicou o contrário. Assim, para análises inferenciais, foi necessário utilizar testes não-paramétricos.

Utilizou-se o teste de correlação de Spearman, para avaliar a correlação entre as concepções de deficiência com a idade dos indivíduos; e o teste Mann-Whitney, para comparar médias, no caso concepções de deficiência com gênero.

A seguir serão expostos os principais resultados gerais e, na sequência, para as duas diferentes categorias de participantes.

\section{Resultados}

Docentes

Os 252 participantes, estavam distribuídos em 112 departamentos acadêmicos, sendo $133(52,8 \%)$ do sexo masculino e $119(47,2 \%)$ do sexo feminino. A idade média dos respondentes foi de 46 anos, com desvio padrão de 9,20, variando entre 28 e 73 anos. Para averiguar normalidade entre a diversidade das respostas, foi utilizado o teste de Shapiro-Wilk, 
que considera uma distribuição normal quando $p>0,05$. A Tabela 1 em seus dados mostra uma distribuição anormal da amostra com base nas concepções da ECD.

Tabela 1 - Teste de Normalidade Docentes

\begin{tabular}{c|c|c|c}
\hline & \multicolumn{3}{|c}{ Shapiro-Wilk } \\
& Estatística & $\mathrm{df}$ & Sig. \\
\hline Social & 0,959 & 241 & 0,000 \\
Biológica & 0,977 & 241 & 0,001 \\
Metafísica & 0,732 & 241 & 0,000 \\
Histórico-Cultural & 0,976 & 241 & 0,000 \\
\hline
\end{tabular}

Fonte: Elaborado pelos autores.

A Tabela 2, traz os achados resultantes da análise estatística descritiva da categoria docentes. Observou-se, a partir das médias calculadas, que a concepção histórico-cultural apresentou a maior pontuação, seguida da social, ou seja, entende-se que esse público tende a concordar com ambas as concepções mencionadas.

Tabela 2 - Média, desvio-padrão e mediana da categoria docentes

\begin{tabular}{c|c|c|c|c}
\hline \multicolumn{1}{c}{ Social } & Biológica & Metafísica & Histórico-cultural \\
\hline Média & $\mathbf{1 1 , 2 0}$ & 7,64 & 5,47 & $\mathbf{1 1 , 9 9}$ \\
\hline DP & 4,10 & 3,59 & 2,16 & 4,32 \\
\hline Mediana & 12 & 7 & 5 & 12 \\
\hline
\end{tabular}

Fonte: Elaborado pelos autores.

No que se refere as correlações das concepções de deficiência e a variável idade, os dados do Teste de Spearman demonstram que não há significância $(p \leq 0,05)$ entre esses parâmetros, conforme demonstrado na Tabela 3. Em outras palavras, não é possível afirmar nesta amostra pesquisada que o grupo apresenta maior ou menor pontuação das concepções com o aumento da idade.

Tabela 3 - Correlação entre as variáveis dimensões e idade nos docentes.

\begin{tabular}{c|c|c|c|c|c}
\hline \multicolumn{2}{c}{ Dimensões } & Social & Biológica & Metafísica & Histórico-cultural \\
\hline \multirow{4}{*}{ Idade } & $\mathrm{r}$ & 0,02 & $-0,02$ & $-0,07$ & 0,10 \\
\cline { 2 - 6 } & $p$ & 0,702 & 0,738 & 0,216 & 0,117 \\
\hline
\end{tabular}

Fonte: Elaborado pelos autores. 
Foram utilizados os parâmetros "dimensões" e "gêneros", buscando avaliar se existe uma diferença significativa entre as médias dos dois conjuntos de participantes, para isso utilizou-se o teste não paramétrico Mann-Whitney. A Tabela 4 a seguir expõe tais resultados.

Tabela 4 - Comparação das variáveis dimensões e gênero nos docentes.

\begin{tabular}{c|c|c|c|c|c}
\hline Dimensões & Gênero & Média & $\mathbf{U}$ & $\mathbf{Z}$ & $\boldsymbol{p}$ \\
\hline \multirow{2}{*}{ Social } & Masculino & 115,53 & & & \\
\cline { 2 - 6 } & Feminino & 134,54 & 6488,50 & $\mathbf{- 2 , 0 9 0}$ & $\mathbf{0 , 0 3 7}$ \\
\hline \multirow{2}{*}{ Biológica } & Masculino & 127,93 & & & \\
\cline { 2 - 6 } & Feminino & 121,69 & 73335,00 & $-0,685$ & 0,493 \\
\hline \multirow{2}{*}{ Metafísica } & Masculino & 120,88 & & & \\
\cline { 2 - 6 } & Feminino & 129,72 & 7166,50 & $-1,116$ & 0,4264 \\
\hline Histórico-cultural & Masculino & 121,02 & & & \\
\hline & Feminino & 127,43 & 7196,00 & $-0,705$ & 0,481 \\
\hline
\end{tabular}

Fonte: Elaborado pelos autores.

Como se pode identificar na Tabela 4, a significância somente foi identificada na dimensão social, nos docentes. Isso significa que as mulheres tendem a concordar mais com a dimensão social do que os homens. Informa-se ainda que o valor negativo de $Z$ indica que o desvio padrão está abaixo da média, demonstrando que a concordância entre as amostras (masculino e feminino) na concepção social são mais homogêneas.

\section{Técnicos}

Este conjunto contou com uma amostra de 232 técnicos administrativos, sendo 138 $(59,5 \%)$ do sexo feminino e $94(40,5 \%)$ do sexo masculino. A idade média dos respondentes foi de 39 anos, com desvio padrão de 9,831, variando entre 22 a 64 anos, demonstrando um público adulto e com predominância feminina.

Como no caso da categoria 'docentes', foi realizado um teste de normalidade da distribuição em virtude do tamanho da amostra. Os resultados apontaram que se tratou de uma amostra anormal, uma vez que $p$ deve ser maior que 0,05 , e no teste de Shapiro-Wilk, para uma distribuição normal. A Tabela 5 mostra o resultado do teste.

Tabela 5 - Teste de Normalidade Técnicos

\begin{tabular}{cccc}
\hline & \multicolumn{3}{c}{ Shapiro-Wilk } \\
\cline { 2 - 4 } & Estatística & Df & Sig. \\
\hline Social & 0,985 & 220 & 0,020 \\
\hline Biológica & 0,978 & 220 & 0,002 \\
\hline Metafísica & 0,893 & 220 & 0,000 \\
\hline Histórico-Cultural & 0,976 & 220 & 0,001 \\
\hline
\end{tabular}

Fonte: Elaborado pelos autores.

Barbarói, Santa Cruz do Sul, n.54, p.<153-170>, jul./dez. 2019 
A Tabela 6 traz os achados resultantes da análise estatística descritiva do segmento técnico-administrativo. Observou-se, a partir das médias calculadas, que a concepção históricocultural apresentou a maior pontuação, seguida da social, ou seja, isso leva a entender esse público tende a concordar com ambas as concepções mencionadas.

Tabela 6 - Média, desvio-padrão e mediana do segmento técnico-administrativo.

\begin{tabular}{c|c|c|c|c}
\hline & Social & Biológica & Metafísica & Histórico-cultural \\
\hline Média & $\mathbf{1 0 , 8 7}$ & 8,70 & 6,32 & $\mathbf{1 1 , 0 4}$ \\
\hline DP & 3,77 & 3,95 & 2,93 & 3,96 \\
\hline Mediana & 11,00 & 8,00 & 5,00 & 11,00 \\
\hline
\end{tabular}

Fonte: Elaborado pelos autores.

As correlações foram verificadas por meio do teste de Spearman, associando as concepções do instrumento com a variável idade, conforme observado na Tabela 7. Dos dados, foram encontradas correlações positivas com as dimensões social, metafisica e históricocultural. Desse modo pode-se dizer que quanto maior a idade mais acentuada é a tendência dos técnicos em acreditarem nas dimensões social, histórico-cultural e metafisica.

Tabela 7 - Correlação entre as variáveis dimensões e idade nos técnicos

\begin{tabular}{c|c|c|c|c|c}
\hline \multicolumn{2}{c|}{ Dimensões } & Social & Biológica & Metafísica & Histórico-cultural \\
\hline & $\mathrm{r}$ & $\mathbf{0 , 1 5}$ & 0,05 & $\mathbf{0 , 2 5}$ & $\mathbf{0 , 1 8}$ \\
\cline { 2 - 6 } Idade & $p$ & $\mathbf{0 , 0 2 4}$ & 0,459 & $\mathbf{0 , 0 0 0}$ & $\mathbf{0 , 0 0 7}$ \\
\hline
\end{tabular}

Fonte: Elaborado pelos autores.

Com relação as possíveis diferenças de médias de respostas nas concepções e em relação a variável gênero, verificou-se pelo uso do teste Mann-Whitney. Percebeu-se que só significância $(p \leq 0,05)$ na dimensão metafísica, esse dado demonstra que o gênero feminino apresentou maior média de resposta (com diferenças significativas) nessa concepção, como pode ser verificado na Tabela 8 . O valor negativo de $\mathrm{Z}$ indica que o desvio padrão está abaixo da média, sugerindo que ambas as amostras (masculino e feminino) possuem homogeneidade em concordância. 
Tabela 8 - Comparação das variáveis dimensões e gênero nos técnicos.

\begin{tabular}{c|c|c|c|c|c}
\hline Dimensões & Gênero & Média & $\mathbf{U}$ & $\boldsymbol{Z}$ & $\boldsymbol{p}$ \\
\hline \multirow{2}{*}{ Social } & Masculino & 118,13 & & & \\
\cline { 2 - 6 } & Feminino & 111,13 & 5773,0 & $-0,764$ & 0,445 \\
\hline \multirow{2}{*}{ Biológica } & Masculino & 125,22 & & & \\
\cline { 2 - 6 } & Feminino & 109,14 & 5440,00 & $-1,798$ & 0,072 \\
\hline \multirow{2}{*}{ Metafísica } & Masculino & 101,17 & & & \\
\cline { 2 - 6 } & Feminino & 124,29 & 5029,50 & $\mathbf{- 2 , 6 3 4}$ & $\mathbf{0 , 0 0 8}$ \\
\hline Histórico-Cultural & Masculino & 108,37 & & & \\
\hline & Feminino & 117,77 & 5675,50 & $-1,060$ & 0,289 \\
\hline
\end{tabular}

Fonte: Elaborado pelos autores.

De maneira geral, quanto aos resultados das duas diferentes categorias de profissionais de participantes da amostra investigada, observam-se algumas semelhanças no modo de se posicionarem diante das concepções de deficiência. Isso pode ser verificado nas análises expostas, demonstrando que, dentro do contexto universitário encontra-se consenso entre a maioria de profissionais, que tende a concordar com concepções social e histórico-cultural.

\section{Discussão}

Ao comparar os resultados obtidos nas duas categorias investigadas percebe-se que algumas semelhanças ocorrem, uma delas consiste em dizer, pela análise das médias e medianas, que os dois conjuntos de participantes tendem a concordar mais com posicionamentos que entendem a deficiência dentro de uma perspectiva social e/ou histórica. Vilela e Leite (2017), Tanaka (2007) e Leite et al. (2018) abordam que conforme maior a identificação da deficiência como um fenômeno de ordem social, melhores serão as relações e atitudes favoráveis à inclusão, sendo que essas condutas são importantes para promover mudanças nos diversos contextos sociais. Em complementar, entende-se que a concepção social emerge por atitudes, condutas e discursos da população geral, ou seja, a promoção e manutenção de interpretações da deficiência por uma determinada concepção é dada a partir de interpretações pela nossa comunidade verbal e por discussões feitas acerca delas (BALEOTTI; OMOTE, 2014; OMOTE, 1996).

A outra concepção com maior pontuação no estudo, a histórico-cultural, para Leite e Mattos (2016, p. 156) se refere que "[...] a deficiência extrapola as condições orgânicas, funcionais ou comportamentais diferenciadas, pois o prejuízo individual está fortemente atrelado a relação que a sociedade mantém com este indivíduo". Nessa perspectiva, o fenômeno 
da deficiência se não restringe ao indivíduo, ou a disfunção orgânica, mas é estabelecida a partir do orgânico e sua relação com o social.

No entanto, a literatura mostra que a sociedade ainda tende a interpretar a deficiência como um fenômeno estritamente biológico, principalmente por compactuar com um ideal médico que ressalta a disfunção orgânica em detrimento da relação do indivíduo com a sociedade (TIJIBOY; HOGETOP, 2001). No presente estudo os achados foram contrários a essa constatação, isso pode ter ocorrido em virtude da pesquisa se concentrar num contexto universitário público, em que supostamente as discussões sobre minorias sociais são debatidas numa perspectiva mais ampla e crítica.

Quanto às análises de correlações nas duas amostras, pode-se perceber correlações positivas e significativas em algumas concepções com a variável idade, fato ocorrido apenas para os técnicos-administrativos. De forma mais específica, quanto maior a idade, maior a tendência desse grupo em concordar com três concepções (metafisica; histórico-cultural; e social).

Acerca da associação positiva entre idade e concepção metafísica, uma hipótese pode ser em virtude de que a quanto mais velho for o indivíduo é mais provável que esse possua maior inclinação religiosa (MOREIRA-ALMEIDA et al., 2010). A religião, posta como instituição pode favorecer enfrentamentos diante de situações atípicas relacionadas a vida e saúde, o presente trabalho não se pautará em julgar esse enfrentamento como positivo ou negativo, mas preocupa-se em afirmar que a concepção metafisica a respeito do fenômeno da deficiência é uma possibilidade de se olhar para o fenômeno e compreende-lo a partir de pressupostos coerentes com sua prática religiosa, para entender melhor, sugere-se a leitura de Faria e Seidl (2005). Segundo Pereira (2006), muitas concepções que se distanciam do modelo religioso se aplicam no discurso formal, mas é posto em comentários e terminologias que assegura uma situação de benevolência e caridade com as pessoas com deficiência, demonstrando que esse viés não foi superado. A concepção metafisica, por exemplo, aborda que a deficiência é um carma ou uma benção, e contribui para atitudes discriminatórias de benevolência e caridade.

Conforme já sinalizado a tendência de aumento de concordância com as concepções social e histórico-cultural quando comparada à idade, pode ser interpretada a partir da maior vivência em contexto universitário, em que a formação de concepções mais críticas são mais presentes e pensando nessa direção o fato de técnico-administrativos participarem desse espaço podem desenvolver visões mais críticas de fenômenos socioculturais. 
Outro dado importante a se discutir é a respeito das generalizações de concepções conforme a variável gênero. Das diferenças com significância estatística na amostra estudada, houve diferenças entre postos de médias na concepção social (entre os docentes) e em metafísica (nos funcionários técnicos). Em ambos, mulheres apresentaram postos de médias superiores. Nos docentes uma hipótese que possa justificar é o ambiente universitário, em especifico o de produção acadêmica, que acaba de um modo ou outro a refletir criticamente sobre fenômenos sociais, numa visão mais crítica, até por conta de terem maior qualificação, afinal grande parte do corpo docente da instituição investigada apresenta doutorado concluído. Quanto aos dados encontrados nos funcionários técnicos, uma hipótese para justificar pode ser dada pelo envolvimento das mulheres com crenças e religiões ser mais expressivos em nossa cultura (ROSADO-NUNES, 2005). No entanto, ressalta-se que, segundo o autor embora dados estatísticos confirmem que a mulher invista mais em religião, essa visão esconde que a produção do "sagrado" nas diversas sociedades é área de predominância masculina. As crenças nessa perspectiva são produzidas por homens, porém reproduzidas e mantidas em predominância pelas mulheres.

Sinteticamente, numa perspectiva mais analítica pautada na leitura de Vigotski (2001), compreender a formação de um conceito nominativo não é tarefa simples, pois exige que se analise como o sujeito se apropria dos conceitos veiculados nas relações sociais que estabelece, entendendo que essas carregam ideologias e interesses de determinados grupos dominantes. A conceituação de algo, dado como objetiva, na realidade posta se configura como subjetiva, influenciada por quem a define e por quem a mantém - no contexto veiculado e datado historicamente. No entanto, o modo como cada indivíduo conceitua vai além do universal e passa para a esfera particular, estando atrelado a sua experiência - contato direto ou indireto mediado pelos significados sociais associados ao fenômeno em questão. Nesse direcionamento, diferenças corporais, sensoriais e/ou comportamentais (de um sujeito ou do grupo ao qual pertence) podem ser classificadas como vantajosas ou não, dependendo da lógica que fundamenta e regulamenta o contexto social em análise. Ao entender que o psiquismo humano se forma pela apropriação dos conceitos que transitam nos processos interacionais, que se engendram em comunidades culturais, tem-se a produção de significados e sentidos que medeiam o modo de pensar, sentir e agir do humano. Isso implica, nas palavras de em considerar [...] que o sujeito, cada vez mais, pode ampliar suas trocas com o mundo e, assim, expandir as representações do meio ao seu redor, formar novos conceitos, e desenvolver a consciência de si e da realidade (SOUZA; ANDRADA, 2013, p. 358). 


\section{Considerações finais}

A universidade como instituição de ensino, deve ser espaço que discuta criticamente as condições culturais de grupos minoritários, no caso aqui retratado o de pessoas com deficiências, uma vez que a sua participação nas instâncias sociais pode ser inviabilizado em função de barreiras atitudinais, que se configuram por práticas discriminatórias que podem, inclusive, dificultar e/ou impossibilitar o acesso e/ou a permanência de pessoas com deficiência em diferentes instâncias sociais. Nesse sentido, é importante que as instituições estabeleçam atividades que visem desconstruir preconceitos e estereótipos junto aos seus funcionários, ou seja, há de se investir em políticas internas e na cultura das organizações na intenção de promover um contexto mais inclusivo e sensível às diferenças, e isso é função da Psicologia. Como pode ser verificado nas análises, dentro do contexto universitário encontramos consenso considerável de uma maioria de indivíduos que tendem a concordarem com concepções que entendam a deficiência numa perspectiva mais social e/ou cultural.

Os profissionais devem estar cientes de que suas condutas são influenciadas por suas concepções, e que há concepções que incluem e outras que excluem grupos sociais (CARVALHO-FREITAS, 2007; CARVALHO- FREITAS; MARQUES, 2010). Convergindo com as representações sociais, há uma implicação direta de como você concebe o fenômeno para como você se orienta frente a ele. As barreiras atitudinais, em especial, são fortemente atreladas a maneira que se concebe o fenômeno, uma concepção que percebe a deficiência como limitada a uma diferença restrita ao orgânico, por exemplo, dificilmente se preocupará com práticas voltadas para mudanças de barreiras no âmbito social, por não identificar relação do meio com o sujeito onde este último vira o estigma da deficiência. Nesse sentido, é necessário que se conheça as implicações de comportamentos e discursos que excluem populações marginalizadas, o que compreende, por exemplo, pessoas discriminadas por etnias, culturas, ou ainda aquelas que apresentam alguma deficiência. Os impactos da exclusão influenciam diretamente a cultura e o clima organizacional, sendo que comportamentos discriminatórios e preconceituosos podem ser reflexos de uma organização pouco compromissada em atender aos princípios éticos e às responsabilidades sociais.

As barreiras atitudinais podem influenciar as relações interpessoais, no acesso ao trabalho e as oportunidades sociais, e consequentemente no desenvolvimento humano. Pautada em princípio éticos a psicologia, como ciência e profissão, procura reverter esses obstáculos na busca da melhor qualidade de vida para todos, e esse compromisso se estende para o contexto das organizações. Nessa perspectiva mostra-se importante que os profissionais da área da psicologia, em particular da psicologia organizacional e do trabalho, estejam preocupados em Barbarói, Santa Cruz do Sul, n.54, p.<153-170>,jul./dez. 2019 
conhecer quais concepções de deficiência circulam no interior nos espaços laborais, uma vez que essas implicam na promoção da saúde e do bem-estar de todos os trabalhadores. Dito de outro modo, é oportuno identificar o que os empregadores e empregados pensam a respeito, principalmente se considerarmos que a participação de pessoas com deficiência tem se tornado cada vez mais comum em função das de políticas públicas que tem considerado essa demanda, como as ações afirmativas dispostas na Lei de Cotas $n^{\circ} .8 .213 / 91$ ou ainda na Lei Brasileira de Inclusão $n^{\circ} .13 .146 / 15$.

A literatura nos mostra que conforme maior a identificação da deficiência como um fenômeno como de ordem social, melhores serão as relações e atitudes favoráveis à inclusão e que visem mudanças na ordem da práxis social (VILELA, 2013; TANAKA, 2007). A partir desta perspectiva mostra-se importante interessante investigar futuramente o quanto o discurso se aproxima ou se distancia das práticas que possam contribuir para uma sociedade inclusiva, ou seja, será que as suas concepções são semelhantes aos seus comportamentos no trato com esse grupo social?

A Psicologia, em especial a Psicologia Organizacional e do Trabalho, nesse contexto, muito pode contribuir na promoção de intervenções ou de projetos educativos que visem desconstruir barreiras atitudinais dirigidas as pessoas com deficiência, refletindo sobre o fenômeno numa perspectiva mais contextualizada, uma vez que o fato de alguém apresentar uma condição orgânica diferenciada não o faz um sujeito de menor valia. Tais ações devem ser pensadas e discutidas como essenciais para que a instituição, ou a organização, se caracterize de fato como um ambiente inclusivo.

\title{
DISABILITY CONCEPTIONS IN PROFESSIONALS OF A UNIVERSITY FROM THE INTERIOR OF SÃO PAULO
}

\begin{abstract}
The participation of people with disabilities in different professional bodies has been a reality more and more frequent due to the public policies that have guided this practice. The present study sought to identify the conceptions of disability in two different categories of professional performance of a public university in the State of São Paulo, namely: teachers and administrative technicians. It starts from the idea that the conceptions about certain phenomena are guiding to the conducts on the same, in the case, the treatment with respect to the people with deficiencies. The Disability Conceptions Scale (ECD), as a data collection instrument, was applied with the two sets of participants. The data were exposed descriptive and inferential analyzes. The results indicated that both teachers and technicians tend to agree with statements that are consistent with conceptions that seek to interpret disability in a more social and cultural perspective. These findings are important for Psychology professionals, particularly those in the organizational and work area, to think of ways of acting so that organizations can in fact be
\end{abstract}


constituted as a welcoming space for differences, with a view to the development of different social groups.

Keyword: People with disabilities, Conception, Organization.

\section{Referências}

BALEOTTI, L. R.; OMOTE, S. A concepção de deficiência em discussão: ponto de vista de docentes de Terapia Ocupacional. Cadernos de Terapia Ocupacional da UFSCar, São Carlos, v. 22, n. 1, p. 71-78, 2014. Disponível em:

<http://doi.editoracubo.com.br/10.4322/cto.2014.008>.

BRASIL. Lei Federal $\mathbf{n}^{\mathbf{0}}$. 12.711, de 29 de agosto de 2012. Dispõe sobre o ingresso nas universidades federais nas instituições federais de ensino técnico de nível médio e dá outras providências. Disponível em: <http://www.planalto.gov.br/ccivil_03/_ato2011-

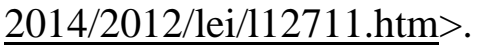

BRASIL. Lei Federal nº 13.146, de 6 de julho de 2015. Institui a Lei Brasileira de Inclusão da Pessoa com Deficiência (Estatuto da Pessoa com Deficiência). Disponível em: <http://www.planalto.gov.br/ccivil_03/_ato2015-2018/2015/lei/113146.htm>.

BRASIL. Lei Federal $\mathbf{n}^{\mathbf{0}}$. 13.409, de 28 de dezembro de 2016. Altera a Lei ${ }^{\mathbf{0}} 12.711$, de 29 de agosto de 2012, para dispor sobre a reserva de vagas para pessoas com deficiência nos cursos técnico de nível médio e superior das instituições federais de ensino. Disponível em: < http://www.planalto.gov.br/ccivil_03/_ato2015-2018/2016/lei/L13409.htm>.

BRASIL. Lei Federal $\mathbf{n}^{0}$. 8.213, de 24 de julho de 1991. Dispõe sobre os Planos de benefícios da Previdência Social e dá outras providências. Disponível em:

<http://www.planalto.gov.br/ccivil_03/leis/L8213cons.htm>.

CARVALHO-FREITAS, M. N. A inserção de pessoas com deficiência em empresas brasileiras: um estudo sobre as relações entre concepções de deficiência, condições de trabalho e qualidade de vida no trabalho. 2007. 314 f. Tese (Doutorado em Administração) Faculdade de Ciências Econômicas, Universidade Federal de Minas Gerais, Belo Horizonte, 2007. Disponível em: 〈https://repositorio.ufmg.br/handle/1843/CSPO-72UKVU>.

CARVALHO-FREITAS, M. N.; MARQUES, A. L. Formas de ver as pessoas com deficiência: um estudo empírico do construto de concepções de deficiência em situações de trabalho. Revista de Administração Mackenzie (RAM), São Paulo, v. 11, n. 3, p. 100-129, mai./jun. 2010. Disponível em: < http://www.scielo.br/scielo.php?script=sci_arttext\&pid=S1678-69712010000300007>.

DINIZ, D. O que é deficiência. São Paulo: Brasiliense, 2007. 89 p. (Coleção Primeiros Passos). Disponível em: < http://www.museusacessiveis.com.br/arquivosDown/20190204153017_o_que_c\%C2\%A9_de ficic\%C2\%AAncia_-_dc\%C2\%A9bora_diniz.pdf $>$.

DINIZ, D. Modelo social da deficiência: A crítica feminista. Letraslivres, Série Anis, v.28, p.1-8, 2003. Disponível em: 
〈http://repositorio.unb.br/bitstream/10482/15250/1/ARTIGO_ModeloSocialDeficiencia.pdf $>$. Acesso em: 13/08/2019.

FARIA, J. B.; SEIDL E. M. F. Religiosidade e enfrentamento em contextos de saúde e doença: revisão da literatura. Psicologia: Reflexão e Crítica, v. 18, n. 3, p. 381-389, 2005. Disponível em: < http://www.scielo.br/scielo.php?pid=S0102-

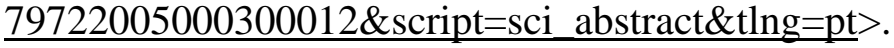

GESSER, M.; NUERNBERG, A. H.; TONELI, M. J. F. A contribuição do modelo social da deficiência à psicologia social. Psicologia Social, Belo Horizonte, v. 24, n. 3, p. 557-566, 2012. Disponível em: < https://pdfs.semanticscholar.org/9147/1d687eb65bc50c550f52f3dfed854f411484.pdf?_ga=2.1 4874623.853396221.1574097640-682322255.1574097640>.

GOFFMAN, E. Estigma - notas sobre a manipulação da identidade deteriorada. 4. ed. Rio de Janeiro: LTC, 1998/1963. Disponível em: < http://www.aberta.senad.gov.br/medias/original/201702/20170214-114707-001.pdf >.

LEITE, L. P.; OLIVEIRA, T,; SERRANO, E. P. Concepções de deficiência em universitários em dois países politicamente distintos: Cuba e Brasil. Diálogos e Perspectivas em Educação Especial, v. 5, p. 95-110, 2018. Disponível em: < http://revistas.marilia.unesp.br/index.php/dialogoseperspectivas/article/view/8337> .

LEITE, L.; OLIVEIRA, T. A concepção social de deficiência sendo superada pelo entendimento biológico ou metafísico. Anais de evento: VIII Simpósio Internacional em Educação e Filosofia - Entre o governo das diferenças e os corpos ingovernáveis: potência da vida na educação, 14p., 2019. Disponível em:

$<$ http://www.inscricoes.fmb.unesp.br/publicacao.asp?codTrabalho=MzAzNTM=>.

LEITE, L. P.; MATTOS, B. M. Aplicação da Escala de Concepções de Deficiência (ECD) em uma universidade pública do Brasil. Journal of Research in Special Educational Needs, v. 16, p. 155-158, 2016. Disponível em: <https://onlinelibrary.wiley.com/doi/full/10.1111/14713802.12277>.

LEITE, L. P.; LACERDA, C. A construção de uma escala sobre as concepções de deficiência. Psicologia USP, v. 29, n.3, p. 432-441, 2018. Disponível em: < http://www.revistas.usp.br/psicousp/article/view/154630 .

MOREIRA-ALMEIDA, A.; PINSKY, I.; ZALESKI, M.; LARANJEIRA, R. Envolvimento religioso e fatores sociodemográficos: resultados de um levantamento nacional no Brasil.

Revista de Psiquiatria Clínica, v. 37, p.12-15, 2010. Disponível em: < http://www.scielo.br/scielo.php?pid=S0101$60832010000100003 \&$ script $=$ sci_abstract\&tlng $=\mathrm{pt}>$.

NEPOMUCENO, M. F. Apropriação no Brasil dos estudos sobre deficiência: uma análise sobre o modelo social. Tese de doutorado. Programa de Pós-graduação em Educação e Docência, Universidade Federal de Minas Gerais, 171p., 2019. Disponível em: < https://repositorio.ufmg.br/bitstream/1843/30490/1/Tese-Maristela-Ferro-Nepomuceno-FaE07-08-2019.pdf>. 
OLIVEIRA, P. A. R.; PANASIEWICZ, R. Tendência religiosa entre a população universitária: um estudo de caso. Horizonte, Belo Horizonte, v. 12, n. 36, p.1160-1189, 2014. Disponível em: < http://periodicos.pucminas.br/index.php/horizonte/article/view/P.2175$\underline{5841.2014 \mathrm{v} 12 \mathrm{n} 36 \mathrm{p} 1160>}$.

OMOTE, S. Estigma no tempo da inclusão. Revista Brasileira de Educação Especial, Marília, v.10, n. 3, p. 287-308, set./dez. 2004. Disponível em: < https://www.abpee.net/homepageabpee04_06/artigos_em_pdf/revista10numero3pdf/3omote.p $\underline{\mathrm{df}}>$.

OMOTE, S. Perspectivas para conceituação de deficiências. Revista Brasileira de Educação Especial, v. 2, n. 4, p. 127-135, 1996.

PALACIOS, A. A Plasmación del modelo social en la Convención Internacional sobre los Derechos de las Personas con Discapacidad. In: El modelo social de discapacidad: orígenes, caracterización y plasmación en la Convención Internacional sobre los Derechos de las Personas con Discapacidad. Madrid: Cermi Ediciones Cinca, 524p., 2008. Disponível em: < https://www.cermi.es/sites/default/files/docs/colecciones/Elmodelosocialdediscapacidad.pdf

PEREIRA, R. J. Anatomia da diferença: uma investigação teórico-descritiva da deficiência à luz do cotidiano. 2006, 174 f. Tese (Doutorado em Saúde Pública) - Escola Nacional de Saúde Pública Sérgio Arouca, Fundação Oswaldo Cruz, Rio de Janeiro, 2006. Disponível em: $<$ https://www.arca.fiocruz.br/handle/icict/4375>.

ROSADO-NUNES, M. J. Gênero e religião. Revista Estudos Feministas, Florianópolis, v. 13, n. 2, mai./ago. 2005. Disponível em: <

https://periodicos.ufsc.br/index.php/ref/article/view/S0104-026X200500020010/7836>.

SOUZA, V. L. T. de; ANDRADA, P. C. de. Contribuições de Vigotski para a compreensão do psiquismo. Estudos de Psicologia (Campinas), v. 30, n. 3, p. 355-365, Set. 2013

Disponível em: http://www.scielo.br/scielo.php?script=sci_arttext\&pid=S0103166X2013000300005\&lng=en\&nrm=iso.

TANAKA, E, D, O. O desenvolvimento de uma escala de atitudes sociais em relação ao trabalho da pessoa com deficiência. Tese (Doutorado em Educação) - Faculdade de Filosofia e Ciências, Universidade Estadual Paulista Júlio de Mesquita Filho, Marília, 198 f., 2007. Disponível em: < https://repositorio.unesp.br/handle/11449/102263>.

TIJIBOY, A. V.; HOGETOP, L. Ressignificando a Concepção de Deficiência através de Ambientes de Aprendizagem Computacionais Telemáticos. Cadernos de Educação

Especial, v. 2, n. 18, p. 93- 105, 2011. Disponível em: <

https://www.researchgate.net/publication/279462273_Ressignificando_a_concepcao_de_defic iencia_atraves_de_ambientes_de_aprendizagem_computacionais_telematicos $>$.

THOMPSON, A. G. Teacher's beliefs and conceptions: a synthesis of the research. In: GROUWS, D. A. (Org.). Handbook of research in mathematics teaching and learning. New York: MacMillan, p. 127-146, 1996. Disponível em: < http://web.a.ebscohost.com/ehost/ebookviewer/ebook/bmxlYmtfXzQ2OTk1MV9fQU41?sid= 88905c08-ba18-4136-a1c6-c936a48845fa@sdc-vsessmgr03\&vid $=0 \&$ format $=E B \& l p i d=l p \_127 \&$ rid $=0$ > $>$. 
VIGOTSKI, L. S. A construção do Pensamento e da Linguagem. São Paulo: Martins Fontes, 2001. Disponível em: < http://www.campogrande.ms.gov.br/egov/wpcontent/uploads/sites/8/2018/08/Texto-1-Prof-Ronny.pdf $>$.

VILELA, L. O. Concepções sobre o trabalho da pessoa com deficiência: avaliação dos efeitos de uma intervenção realizada com funcionários de uma Universidade pública. 2013. 122 f. Dissertação (Mestrado em Psicologia do Desenvolvimento e Aprendizagem) Faculdade de Ciências de Bauru, Universidade Estadual Paulista Júlio de Mesquita Filho, Bauru, 2013. Disponível em: < https://repositorio.unesp.br/handle/11449/97473?show=full> .

VILELA, L. O.; LEITE, L. P. Effects of an intervention on the participation of people with disability in the workplace. Estudos de Psicologia (Campinas), Campinas, v. 34, n. 1, p. 185-195, mar. 2017. Disponível em: < http://www.scielo.br/scielo.php?script=sci_abstract\&pid=S0103-

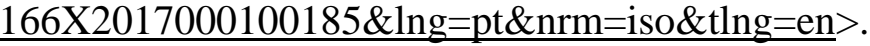

Data de recebimento: $20 / 11 / 2017$

Data de aceite: $13 / 11 / 2019$

\section{Sobre os autores:}

Lucia Pereira Leite é Livre-docente do Departamento de Psicologia - Pós-graduação em Psicologia do Desenvolvimento e Aprendizagem - UNESP - Bauru/SP. Endereço Eletrônico: lucia.leite@unesp.br

Taize de Oliveira é Mestranda no Programa de Pós-graduação em Psicologia do Desenvolvimento e Aprendizagem - UNESP - Bauru/SP. Endereço Eletrônico: taize.oliveira@unesp.br

Hugo Ferrari Cardoso - Docente do Departamento de Psicologia - Pós-graduação em Psicologia do Desenvolvimento e Aprendizagem - UNESP - Bauru/SP. Endereço Eletrônico: hugo.cardoso@unesp.br

O estudo retratado derivou de resultados de pesquisa PIBIC Proc. 103850/2016-3., e faz parte de uma pesquisa maior financiada pelo CNPq Proc. 305575/2017-1 e pela FAPESP Proc. 2017/12721-5. 